
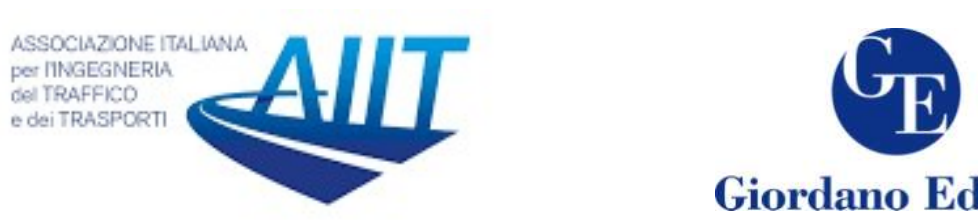

Giordano Editore

\title{
Mode choice of food transport considering heterogeneity among shippers using the latent class analysis
}

\author{
Ansu V ${ }^{1 *}$, M.V.L.R. Anjaneyulu ${ }^{2}$ \\ ${ }^{1}$ Research Scholar, Centre for Transportation Research, National Institute of Technology Calicut, India, \\ ${ }^{2}$ Professor, Centre for Transportation Research, National Institute of Technology Calicut, India,
}

\begin{abstract}
This study is an attempt to identify the heterogeneity in mode choice behaviour of shippers by latent class analysis, using the characteristics of the shippers. Shipping firms were classified into three latent classes: small firms with low truck ownership, large firms with high truck ownership, and long-established firms with no trucks. The study revealed that the mode choice behaviour of the latent classes of shippers is different. Further, it is discovered that the mode share of rail can be increased by decreasing the transportation cost and handling charges, or by increasing the speed and frequency of shipment.
\end{abstract}

Keywords: Freight transport, Heterogeneity, Latent class analysis, Mode choice, Binary logit model, Revealed preference survey.

\section{Introduction}

Efficient movement of freight between locations of production and consumption is vital for the economic growth of a country. Even though energy consumed for freight transport by road is 11.6 times than that by rail, the road takes $61 \%$ of interregional freight in India whereas rail carries only 30\% (Planning commission, 2014). Mode choice analysis, the most policy sensitive stage in four-stage freight demand modelling, helps policymakers to identify the variables that influence the selection of the mode of transport and plan strategies that would improve energy efficiency.

Discrete choice model estimates the probability of choosing an alternative from a set of alternatives based on various factors affecting the decision. Freight mode choice modelling could be done at an aggregate or disaggregate level. Aggregate models give the mode split at the zonal level, and the disaggregate models give the mode choice for the individual shipment. Disaggregate models are more accurate, geographically transferable, and facilitate policy formulation (Ortúzar and Willumsen, 2011). Disaggregate discrete choice modelling is based on the theory of Random utility maximisation, which assumes that the decision-maker chooses the alternative that gives maximum utility. Discrete choice models such as logit regression or probit regression

\footnotetext{
*Corresponding author: Ansu V (ansuva@gmail.com)
} 
techniques are used for mode choice modelling. Wang et al. (2013) compared logit and probit modelling techniques for the freight mode choice and concluded that there is no significant difference in results of both the models. Moreover, logit model is commonly used for mode choice modelling of freight transport (Arunotayanun \& Polak, 2011; de Jong et al., 2004; Grue \& Ludvigsen, 2006; Holguin-Veras, 2002; Jiang et al., 1999; Samimi et al., 2011; G. Shen \& Wang, 2012; Shinghal \& Fowkes, 2002). Hence the logit modelling technique is adopted in this study for choice modelling.

Unlike passenger traffic, the shipper decides the mode of transport for freight. A shipper is a person or a firm that sends or receives goods. Mode choice modelling of freight transport is complicated because of the variation in characteristics of commodity, shipper, distance, and mode of transportation. Earlier studies considered the variation in commodity characteristics by developing separate models for each class of the commodity. However, not all shippers behave similarly in the selection of transport mode for the same commodity. Hence, it may be not proper to develop a mode choice model for the whole population.

Mixed logit model, developed in the late nineties, is used to accommodate the heterogeneity among the data. Mixed logit model has two error components, where one follows the Gumbel distribution, and the other can follow any distribution, such as the normal or lognormal. However, mixed logit modelling is very time consuming, and the choice of the distribution of error components could strongly affect the result (Tavasszy \& Jong, 2014). Several studies found that choice models considering heterogeneity based on latent class analysis outperformed the mixed logit models (Feng et al., 2013; Hess et al., 2011; Puckett \& Rasciute, 2010; J. Shen, 2009). In the case of continuous variables, Magidson \& Vermunt, (2002) proved that that latent class clustering outperforms the traditional K-means algorithm. Román et al. (2017) observed that the latent class model is better for analysing unobserved heterogeneity. Hence, latent class analysis is a stateof-the-art tool to discover heterogeneity in data. It identifies clusters with similar characteristics in a population. The advantages of latent class analysis over traditional types of cluster analysis include probability-based classification, and accommodating many types of variables like continuous, categorical (nominal or ordinal), and count variables. The membership probabilities are estimated from the model parameters. A case is assigned to a latent class for which the membership probability is the highest. Hence, latent class analysis is used to discover the heterogeneity among shippers in this study and mode choice modelling of the latent classes are done separately.

There are limited studies considering heterogeneity in mode choice of freight transport. Kim et al. (2017) analysed heterogeneity in freight shippers' mode choice preferences by grouping the firms based on shipment size. Román et al., (2017) analysed unobserved heterogeneity in preferences and identified the latent classes of shippers as 1) noncompensating cost-sensitive individuals with acceptable service levels, 2) compensating individuals disregarding penalties for time and service frequency, and 3) compensating individuals disregarding delay penalties. Chu (2014) identified the heterogeneous preferences among different categories of air freight forwarders, and the categories were found to perform well in estimating influential factors. Bergantino et al. (2013) found substantial heterogeneity among shippers based on their size. Larger firms tend to assign a lower value to travel time but higher importance to the risk of loss/damage for shipments that are not frequent. Arunotayanun and Polak (2011) reported the existence of significant amounts of taste heterogeneity amongst shippers, especially about service attributes. Their results also indicate that although there are significant differences in tastes between 
commodity segments, a substantial amount of residual heterogeneity remains within each commodity segment.

The hypothesis for this study is that there is heterogeneity among shippers regarding their characteristics, and it is better to analyse mode choice of latent classes of shippers separately.

\section{Methodology}

Food is an essential commodity, which is transported in large volumes. Hence, this study tries to improve the efficiency of food transport. The research focuses on the mode choice behaviour of shippers for the transport of non-perishable food items, having a shelf life over 14 days. Scope of this study is limited to interregional domestic freight and excludes urban and international shipments. Modes of transportation considered in this study are the rail and the road as they transport the major share $(91 \%)$ in India. Rail transport has a small part of the road component at its trip ends to enable door-to-door connectivity, but it is referred to as rail in this study.

The selection of a mode of transport is considered as a decision-making process. The identification of the variables that influence the decision-making process is critical for predicting the freight mode choice (Jiang et al., 1999; Tavasszy \& Jong, 2014). A revealed preference survey of the shippers is employed for data collection.

The variables to be included in the survey questionnaire were identified from the previous studies on freight mode choice by Nuzzolo \& Russo (1998), Jiang et al. (1999), Shinghal \& Fowkes (2002), García-Menéndez et al. (2004), Grue \& Ludvigsen (2006), Rich et al. (2009), Tortum et al. (2009), Arunotayanun and Polak (2011), Samimi et al. (2011), Moschovou \& Giannopoulos (2012), Shen \& Wang (2012), Bergantino et al. (2013), Wang et al. (2013), Mitra and Leon (2014), Reis (2014). The questionnaire was prepared, and a pilot survey among shippers was conducted to assess the sufficiency/deficiency of the questionnaire. The questionnaire was improved after the pilot survey by omitting the insignificant variables.

Details were collected from shippers of food items in different towns/cities in Kerala, the southern state of India by face-to-face interview technique. The minimum sample size was taken as 20 times the number of variables in the model subjected to a minimum of 200 for normality (Hair et al., 2009). The shipments having a distance less than $100 \mathrm{~km}$, were not considered in this study as these shipments were sent by road. The data entry was done after coding the data. The outliers in the data were identified and removed. After checking for errors and data cleaning, 1648 datasets were available for analysis and modelling.

The database was explored to find out the mode choice behaviour of the shippers regarding the various explanatory variables for the selection of the best modelling strategy. Mode choice modelling at the disaggregated level is attempted in this study to find out the significant factors of mode choice. The latent classes of shippers were modelled separately to identify their mode choice. As the present study pertains to transport of non-perishable food items by road and rail, binary logit model is used. 


\section{Data Summary}

Table 1 presents the metric variables considered in the study, including two derived variables, as explained in the following section, along with summary statistics.

Table 1 Summary statistics of the collected data

\begin{tabular}{lcccc}
\hline Observed variable & Minimum & Maximum & Mean & Std. Deviation \\
\hline Age of shipping firm, years & 1 & 115 & 25.9 & 21.9 \\
Number of Employees & 1 & 100 & 7.0 & 13.6 \\
Number of trucks owned & 0 & 14 & 0.3 & 1.3 \\
Distance of transport, km & 100 & 3,274 & 928 & 760 \\
The shelf life of the commodity, days & 15.0 & 365 & 220.9 & 148.3 \\
Weight of shipment, tonnes & 0.02 & 28 & 12.9 & 7.5 \\
Value of shipment, INR & 2,560 & $7,500,000$ & 587,541 & 786,468 \\
Frequency of shipment, per month & 0.10 & 100 & 11.4 & 17.2 \\
Handling charges, INR & 12.0 & 12,000 & 5,055 & 2,890 \\
Transportation time, hours & 2.0 & 192 & 49 & 45.8 \\
Pickup time, hours & 1 & 36 & 2.0 & 3.5 \\
Delivery time, hours & 1 & 24 & 1.7 & 1.1 \\
Capacity of mode, tonnes & 2.5 & 40 & 17.4 & 7.4 \\
Cost of loss, damage or theft, INR & 0.0 & 19,200 & 914.1 & $2,484.6$ \\
Speed, km/h & 5.3 & 66 & 23.8 & 12 \\
Transportation cost per quintal-km, INR/qkm & 8.4 & 479 & 42.4 & 45.9 \\
\hline
\end{tabular}

Table 2 presents the details of the non-metric (categorical) variables, along with the coding. Analysis of the non-metric data collected revealed that $79 \%$ of road shippers and $68 \%$ of rail shippers believe that the respective mode of transport is safe from damage and theft. $97 \%$ of road shippers and $69 \%$ of rail shippers revealed that the respective transport mode is flexible. Shippers believe that the overall service quality and tracking facility of the road is better than rail. In contrast, the reliability of rail transport is found to be better than the road.

Table 2 Non-metric variables

\begin{tabular}{ll}
\hline Non-metric Variable & Description and coding \\
\hline Reliability of the mode of transport & $1=$ low, $2=$ normal, $3=$ high \\
Availability of handling equipment & $0=$ no, $1=$ yes \\
Safety from damage and theft & $0=$ no, $1=$ yes \\
Availability of tracking facility & $0=$ no, $1=$ yes \\
Flexibility of the transport mode & $0=$ no, $1=$ yes \\
Overall service quality & $1=$ poor, $2=$ average, $3=$ good, $4=$ excellent \\
\hline
\end{tabular}

\section{Shippers' attitude on mode choice factors}

The shippers were requested to mark the level of importance on a 5-point Likert scale for each variable. Figure 1 shows the analysis of the importance rating of the mode choice variables. This analysis gives an insight into how shippers perceive different factors in the mode selection. The important factors of mode choice are the availability of mode of transport, reliability, transportation time, cost of transport, accessibility, and weight of the shipment. These factors were considered while modelling the mode choice. The availability of mode of transport can be increased by increasing the frequency of service. The transportation time varies with distance, so the speed of transport is considered in the modelling. 


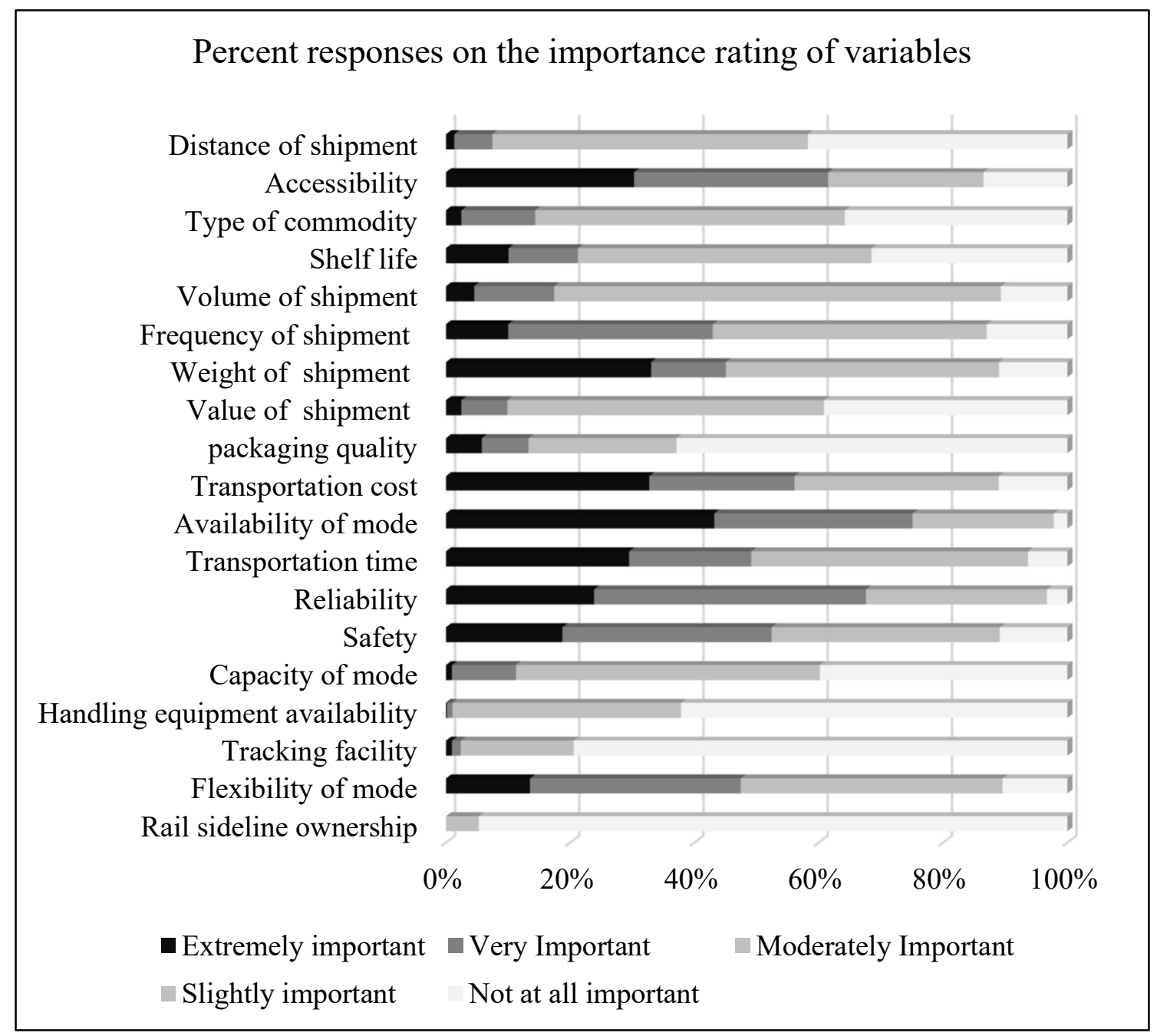

Figure 1 Percent responses on the importance rating of variables

\section{Mode Choice Modelling}

Highly correlated variables can cause errors in mode choice modelling. One method of eliminating this error is by combining these variables to form latent variables. However, it is difficult to interpret the effects of the individual variables of a latent variable in policy analysis. Table 3 presents the results of the correlation analysis of the explanatory variables. Cost of transportation is highly correlated with the weight of the shipment and distance of transport. Transportation time is highly correlated with distance and the cost of transportation. Hence, two variables were derived; 'transportation cost per quintal-km' and 'speed of transportation' for modelling. Transportation cost per quintal-km is the cost of transportation divided by the weight of the shipment and distance of transport. The speed of transportation is the distance divided by the transport time. 
Table 3 Correlation matrix

\begin{tabular}{|c|c|c|c|c|c|c|c|c|c|}
\hline Variable & 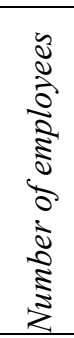 & 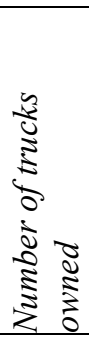 & 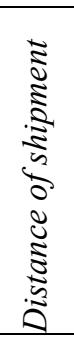 & 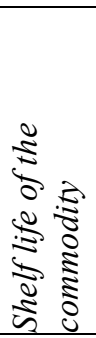 & 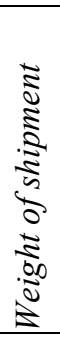 & 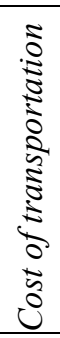 & 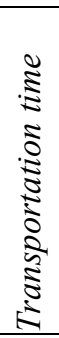 & 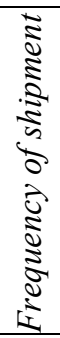 & 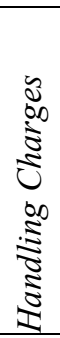 \\
\hline Number of trucks owned & 0.4 & & & & & & & & \\
\hline Distance of shipment & -0.1 & -0.1 & & & & & & & \\
\hline Shelf life of commodity & -0.1 & -0.1 & 0.2 & & & & & & \\
\hline Weight of shipment & 0.0 & 0.0 & 0.2 & 0.4 & & & & & \\
\hline Cost of transportation & -0.1 & -0.1 & 0.8 & 0.3 & 0.5 & & & & \\
\hline Transportation time & -0.1 & -0.1 & 0.9 & 0.3 & 0.3 & 0.8 & & & \\
\hline Frequency of shipment & 0.6 & 0.2 & 0.0 & -0.1 & 0.2 & 0.0 & 0.0 & & \\
\hline Handling charges & 0.0 & 0.0 & 0.2 & 0.4 & 1.0 & 0.5 & 0.3 & 0.2 & \\
\hline
\end{tabular}

The dependent variable is the mode of transport chosen by the shipper. The road is considered as the reference category, and the confidence interval is $95 \%$. Variables with a significance value of less than 0.05 are significant. Variables that are better suited for policy formulation were selected for modelling. Stepwise modelling approach eliminated insignificant variables one by one to obtain the best model. Table 4 presents the mode choice model using the complete dataset. The Chi-square value of the model is 690 and is significant, which indicates that there is a good relationship between the dependent variable and the combination of independent variables. The Nagelkerke $\mathrm{R}^{2}$ of the model is 0.951 , and the classification accuracy is $99.7 \%$.

Table 4 Mode choice model

\begin{tabular}{lrrrrr}
\hline $\begin{array}{l}\text { For Rail } \\
\text { (Reference Category: Road) }\end{array}$ & Coefficient B & $\begin{array}{c}\text { Std. } \\
\text { Error }\end{array}$ & $\begin{array}{c}\text { Wald } \\
\text { statistic }\end{array}$ & Sig. & Exp(B) \\
\hline Intercept & 4.604 & 2.111 & 4.756 & 0.029 & \\
Transportation cost per qkm & -0.136 & 0.032 & 18.163 & 0.000 & 0.872 \\
Speed & 0.137 & 0.039 & 12.69 & 0.000 & 1.147 \\
Shelf life in days & -0.012 & 0.005 & 6.831 & 0.009 & 0.988 \\
Handling charges & -0.005 & 0.001 & 20.126 & 0.000 & 0.995 \\
Shipment frequency per month & 0.119 & 0.033 & 13.15 & 0.000 & 1.126 \\
\hline
\end{tabular}

The coefficient (B) represents the change in log odds of the dependent variable for a unit change in the independent variable. Exponentiated coefficient (Exp (B)) minus one represents the percentage change in the odds of being a member of the modelled event, associated with a unit change in the independent variable. If coefficient B is positive for a variable, its exponentiated coefficient will be higher than one, and the modelled event is more likely to occur with an increase in the variable's value and vice versa. The exponentiated coefficient of the variable 'transportation cost per quintal-km' is 0.872 which implies that, for each unit increase in the variable, the odds of being in the group of survey respondents who choose rail decrease by $12.8 \%(0.872-1=-0.128)$. Besides, for a unit increase in speed, the odds of choosing rail increase by $14.7 \%(1.147-1)$. Hence, the mode share of rail can be increased by decreasing the transportation cost and handling charges. The mode share of rail can also be increased by increasing the speed and 
frequency of shipment. Table 1 shows that there is a significant variation in the characteristics of shippers. Hence, the latent class analysis is proposed to incorporate the shipper's heterogeneity in the mode choice models.

\section{Latent Class Analysis}

Several combinations of the variables corresponding to the characteristics of the shipping firm such as the age of the shipping firm, number of employees, industry type, the structure of the firm, number of trucks owned, and own trucks used for shipment were used in the latent class analysis to find the clusters among the shippers. Out of several sets of variables, the best set is selected as the one that is significant, parsimonious, having high $\mathrm{R}^{2}$ value, a lower number of classes with lower classification error. Akaike Information Criterion (AIC) and Bayesian Information Criterion (BIC) reflect the parsimony of the model. Table 5 presents the results of the latent class analysis using the best combination of variables: the age of the shipping firm, number of employees, number of trucks owned and own trucks used for shipment. The $\mathrm{R}^{2}$ value of the model is 0.976 . The table reports the log-likelihood (LL), BIC based on LL, AIC based on LL, and the proportion of classification errors for the classes. With each set of the variables, the optimum number of classes is the one with the lowest BIC value. Hence, the model with the three classes is selected.

Table 5 Selection of the optimum number of classes for latent class analysis

\begin{tabular}{lcccc}
\hline No. of classes & $L L$ & $B I C(L L)$ & $A I C(L L)$ & Classification error \\
\hline 1-Class & -10611.4 & 21822.8 & 21384.8 & 0.0000 \\
2-Class & -9975.9 & 20589.0 & 20123.9 & 0.0020 \\
3-Class & -9915.1 & $\mathbf{2 0 5 0 4 . 3}$ & 20012.3 & 0.0028 \\
4-Class & -9903.6 & 20518.2 & 19999.1 & 0.0025 \\
\hline
\end{tabular}

Figure 2 presents the profile plot of the latent classes formed. Before plotting the classspecific means of the variables, they are re-scaled to lie within 0 to 1 range, to show on the same scale. The profile plot gives the conditional probabilities of each of the variables for being in a particular cluster. Class 1 is formed with shipping firms having a low number of employees, low truck ownership and little use of own trucks. Class 2 is formed of firms with a higher number of employees having high truck ownership with the majority using their trucks. Shipping firms having a long-standing of more than 100 years with no trucks belong to class 3 . The number of data sets forming Class 1, 2, 3 are 1465, 141 and 42 . The majority (89\%) of shippers belong to Class 1 . As there are distinct latent classes of shippers, mode choice modelling was done for each class separately to account for the taste heterogeneity. 


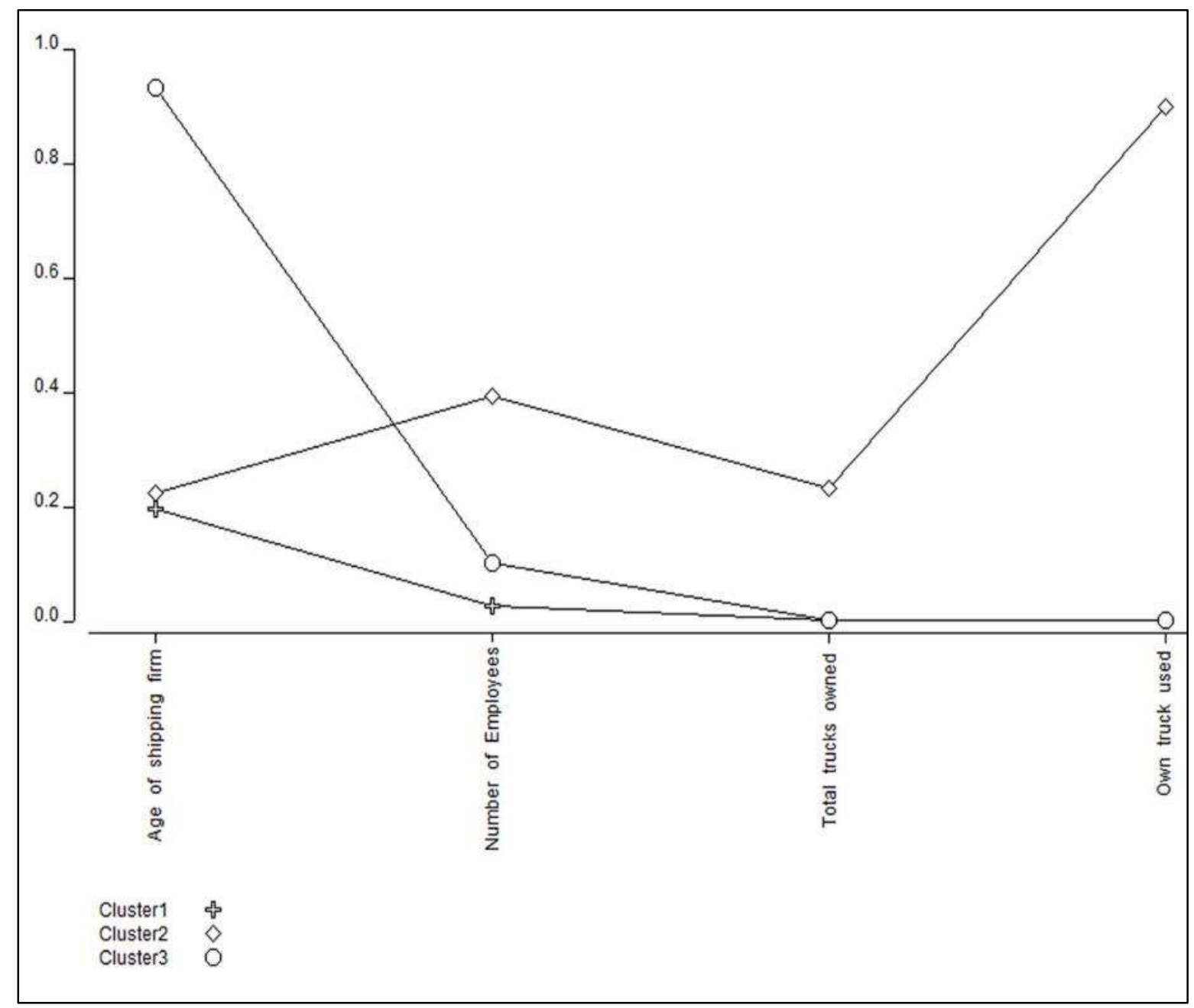

Figure 2 Profile plot of the latent classes formed

\section{Mode Choice Modelling for Latent Classes of Shipping Firms}

Table 6 presents the mode choice model for Latent class 1 . The Nagelkerke $\mathrm{R}^{2}$ of the model is 0.964 , and the classification accuracy is $99.7 \%$. It can be seen that the mode share of rail can be increased by decreasing the transportation cost and handling charges, or by increasing the speed and frequency of shipment.

Table 6 Mode choice model for Latent class 1

\begin{tabular}{lrrrrr}
\hline For Rail & Coefficient & \multicolumn{1}{c}{ Std. } & Wald & Sig. & Exp(B) \\
(Reference Category: Road) & $B$ & Error & statistic & & \\
\hline Intercept & 4.149 & 2.591 & 2.564 & 0.109 & \\
Transportation cost per quintal-km & -0.162 & 0.04 & 16.629 & 0.000 & 0.85 \\
Speed & 0.133 & 0.052 & 6.523 & 0.011 & 1.142 \\
Shelflife in days & -0.017 & 0.008 & 4.1 & 0.043 & 0.983 \\
Handling charges & -0.004 & 0.001 & 9.617 & 0.002 & 0.996 \\
Shipment frequency per month & 0.401 & 0.152 & 6.942 & 0.008 & 1.493 \\
\hline
\end{tabular}

$96.5 \%$ of the shippers' of latent class 2 use road, which comprises large shipping firms with a high number of trucks and its usage. As the majority in this class have only one 
choice, there is no need for choice modelling. Without considering the heterogeneity among shippers in modelling, the distinct behaviour of this group remains hidden.

All the shipping firms that belong to class 3 prefer the road, probably because they are having a long-standing of more than 100 years and are therefore inclined to go by the traditional means of transportation. Since all the shippers of class 3 use road, there is no need for choice modelling, and the classification accuracy is $100 \%$. Hence, it is clear that the shippers of different latent classes behave differently in selecting the mode of transport.

\section{Conclusions}

This paper examined the existence of heterogeneity among the shippers of food items. Results of the latent class analysis revealed that there are three distinct groups among shippers. Small shipping firms with low truck ownership form the first group. The second group is formed by large shipping firms having high truck ownership. Long established shipping firms who do not own trucks form the third group. Majority of shippers of the second group select road for transport of food items, as they own trucks. All the shipping firms of the third group prefer the road.

Shipping firms of the first group select mode of transport for food items based on transportation cost, speed, shelf life, handling charges, and the shipment frequency. The mode share of rail can be increased by decreasing the transportation cost and handling charges, or by increasing the speed and frequency of shipment. The cost of rail freight transport can be reduced by reducing the cross-subsidy given to passenger transport. Railways can increase the speed and frequency of freight transport by providing more dedicated freight corridors, enhancing containerisation and Roll-on roll-off facility. Railways can also start new special trains for the parcels and piecemeal service of freight.

The study revealed that latent class analysis improved the understanding of mode choice behaviour of shippers. Mode choice modelling of latent classes is better than developing a single model for the whole population as different latent classes of shippers have different preferences. Researchers can take forward this method for other commodities.

\section{References}

Arunotayanun, K., \& Polak, J. W. (2011). Taste heterogeneity and market segmentation in freight shippers' mode choice behaviour. Transportation Research Part E: Logistics and Transportation Review, 47(2), 138-148.

Bergantino, A. S., Bierlaire, M., Catalano, M., Migliore, M., \& Amoroso, S. (2013). Taste heterogeneity and latent preferences in the choice behaviour of freight transport operators. Transport Policy, 30, 77-91. https://doi.org/10.1016/j.tranpol.2013.08.002

Chu, H.-C. (2014). Exploring preference heterogeneity of air freight forwarders in the choices of carriers and routes. Journal of Air Transport Management, 37, 45-52. https://doi.org/10.1016/J.JAIRTRAMAN.2014.02.002

de Jong, G., Gunn, H., \& Walker, W. (2004). National and International Freight Transport Models: An Overview and Ideas for Future Development. In Transport Reviews (Vol. 24, Issue 1, pp. 103-124).

Feng, T., Arentze, T., \& Harry, T. (2013). Capturing preference heterogeneity of truck drivers' route choice behavior with context effects using a latent class model. Ejtir, 259273.

García-Menéndez, L., Martínez-Zarzoso, I., \& Pinero De Miguel, D. (2004). Determinants 
of mode choice between road and shipping for freight transport: Evidence for four Spanish exporting sectors. Journal of Transport Economics and Policy, 38(3), 447-466.

Grue, B., \& Ludvigsen, J. (2006). Decision Factors Underlying Transport Mode Choice in International European Freight Transport.

Hair, J. J. F., Black, W. C., Babin, B. J., \& Anderson, R. E. (2009). Multivariate Data Analysis. In Prentice Hall (7th ed.). Pearson.

Hess, S., Ben-Akiva, M., \& Gopinath, D, J. W. (2011). Advantages of latent class models over continuous mixture models in capturing heterogeneity. European Transport Trasporti Europei.

Holguin-Veras, J. (2002). Revealed Preference Analysis of Commercial Vehicle Choice Process. In Journal of Transportation Engineering (Vol. 128, Issue 4, pp. 336-346).

Jiang, F., Jonhson, P., \& Calzada, C. (1999). Freight Demand Characteristics and Mode Choice: An Analysis of the Results of Modeling with Disaggregate Revealed Preference Data. Journal of Transportation and Statistics, 149-158.

Kim, H.-C., Nicholson, A., \& Kusumastuti, D. (2017). Analysing freight shippers' mode choice preference heterogeneity using latent class modelling. Transportation Research Procedia, 25, 1109-1125. https://doi.org/10.1016/J.TRPRO.2017.05.123

Magidson, J., \& Vermunt, J. K. (2002). Latent class models for clustering: A comparison with K-means. Canadian Journal of Marketing Research, 20, 37-44.

Mitra, S., \& Leon, S. M. (2014). Discrete choice model for air-cargo mode selection. International Journal of Logistics Management, 25(3).

Moschovou, T. P., \& Giannopoulos, G. A. (2012). Modeling Freight Mode Choice in Greece. Procedia - Social and Behavioral Sciences, 48, 597-611.

Nuzzolo, A., \& Russo, F. (1998). A Logistic Approach for Freight Modal Choice Model. Transportation Planning Methods. Proceedings of Seminar Held at AET European Transport Conference, Loughborough University, UK, 14-18 September 1998. Volume P424.

Ortúzar J.D., \& Willumsen, L. G. (2011). Modelling Transport. Wiley.

Planning commission, I. (2014). Total transport system study on traffic flows and modal costs (Highways, Railways, Airways and Coastal shipping), A study by RITES Ltd.

Puckett, S., \& Rasciute, S. (2010). Freight stakeholders' sensitivities under road user charging: a latent class approach. Australasian Transport Research Forum 33rd.

Reis, V. (2014). Analysis of mode choice variables in short-distance intermodal freight transport using an agent-based model. Transportation Research Part A: Policy and Practice, 61, 100-120. https://doi.org/10.1016/j.tra.2014.01.002

Rich, J., Holmblad, P. M., \& Hansen, C. O. (2009). A weighted logit freight mode-choice model. Transportation Research Part E: Logistics and Transportation Review, 45(6), 1006-1019.

Román, C., Arencibia, A. I., \& Feo-Valero, M. (2017). A latent class model with attribute cut-offs to analyse modal choice for freight transport. Transportation Research Part A: Policy and Practice, 102, 212-227. https://doi.org/10.1016/J.TRA.2016.10.020

Samimi, A., Kawamura, K., \& Mohammadian, A. (2011). A behavioral analysis of freight mode choice decisions. Transportation Planning and Technology, 34(8), 857-869.

Shen, G., \& Wang, J. (2012). A Freight Mode Choice Analysis Using a Binary Logit Model and GIS: The Case of Cereal Grains Transportation in the United States. Journal of Transportation Technologies, 02(02), 175-188.

Shen, J. (2009). Latent class model or mixed logit model? A comparison by transport mode choice data. Applied Economics, 41, 2915-2924. 
https://doi.org/10.1080/00036840801964633

Shinghal, N., \& Fowkes, T. (2002). Freight mode choice and adaptive stated preferences. Transportation Research Part E: Logistics and Transportation Review, 38(5), 367-378. Tavasszy, L., \& Jong, G. de. (2014). Modelling freight transport. Elsevier Science.

Tortum, A., Yayla, N., \& Gökdağ, M. (2009). The modeling of mode choices of intercity freight transportation with the artificial neural networks and adaptive neuro-fuzzy inference system. Expert Systems with Applications, $36(3$ PART 2), 6199-6217. https://doi.org/10.1016/j.eswa.2008.07.032

Wang, Y., Ding, C., Liu, C., \& Xie, B. (2013). An Analysis of Interstate Freight Mode Choice between Truck and Rail: A Case Study of Maryland, United States. Procedia Social and Behavioral Sciences, 96, 1239-1249.

\section{Acknowledgement}

We sincerely thank the shippers of Kerala for their support and providing the proprietary data. We are also grateful for financial support from the Centre for Transportation Research, National Institute of Technology Calicut, India, for conducting surveys. 